\title{
PENGARUH SOFT SKILL DAN LOCUS OF CONTROL TERHADAP KESIAPAN FRESH GRADUATE DALAM ERA INDUSTRI 4.0 (STUDI PADA PRODI MANAJEMEN UNIHAZ BENGKULU) \\ Fauzan, SE., M.M \\ fauzanunihaz@gmail.com
}

\begin{abstract}
Abstrak
Sifat penelitian ini adalah eksplanatory risearach, yaitu untuk mengetahui hubungan variabel soft skill $\left(\mathrm{X}_{1}\right)$ dan locus of control $\left(\mathrm{X}_{2}\right)$ dengan kesiapan fresh graduate dalam era industri 4.0 (Y) dan menguji hipotesa. Penelitian ini menggunakan data kuantitatif yang berasal dari penyebaran kuesioner kepada reponden kemudian diolah kedalam analisa statistik.

Hasi analisis diperoleh (1) variabel soft skill $\left(\mathrm{X}_{1}\right)$ dan Locus Of Control Internal $\left(\mathrm{X}_{2}\right)$ berpengaruh positif terhadap kesiapan fresh graduate dalam era industri 4.0 (Y). Hal tersebut ditunjukkan oleh regrasi berganda, korelasi berganda, determinasi, uji-t dan uji-f. (2) Variabel soft skill memberikan kontribusi yang lebih besar dibandingkan dengan Locus Of Control Internal dalam menumbuhkan kesiapan menghadapi era industri 4.0 bagi lulusan prodi manajemen Unihaz Bengkulu yang menyelesaikan masa studinya..

Sebagai saran, mahasiswa diberikan pasilitas dan kesempatan untuk mengembangkan soft skill seperti mengikuti organisasi kemahasiswaan, organisasi kerohanian dan mengikuti lomba-lomba untuk pengembangan diri. Disamping itu perlu ditumbuh dan kembangkan rasa percaya diri agar lulusan yang baru menyelesaikan studi tetap optimis dalam menatap masa depan dalam era industri 4.0
\end{abstract}

Kata kunci : Soft Skill, Locus Of Control Internal dan Fresh Graduate, era industri 4.0

\begin{abstract}
The nature of this research is explanatory research, which is to find out the relationship between soft skill (X1) and locus of control (X2) variables with fresh graduate readiness in industrial era 4.0 (Y) and test hypotheses. This study uses quantitative data derived from distributing questionnaires to respondents and then processed into statistical analysis.

The results of the analysis were obtained (1) soft skill variables (X1) and Internal Locus of Control (X2) had a positive effect on fresh graduate readiness in the industrial era 4.0 (Y). This is indicated by multiple regrations, multiple correlations, determination, t-test and f-test. (2) The soft skill variable gives a greater contribution compared to the Internal Locus of Control in fostering readiness to face the industry era 4.0 for graduates of the management program at Unihaz Bengkulu who completed their studies.

As a suggestion, students are given the facilities and opportunities to develop soft skills such as participating in student organizations, spiritual organizations and competing in competitions for self-development. Besides that, it is necessary to
\end{abstract}


grow and develop confidence so that graduates who have just completed their studies remain optimistic in looking at the future in the industrial era 4.0

Keywords: Soft Skill, Internal Locus of Control and Fresh Graduate, industrial era 4.0

\section{Pendahuluan}

Sejak di canangkan tahun 2011 era industri 4.0 ditanggapi beragam oleh masyarakat dunia. Ada yang memandang sebagai peluang dan berbagai harapan positif yang tersedia, namun banyak pula yang memandang sebagai suatu hal yang menakutkan dan menghawatirkan. Industri 4.0 telah mengubah peradaban masyarakat. Banyak pekerjaan yang dulu sangat dipaforitkan tiba-tiba hilang seperti tidak ada sama sekali, demikian sebaliknya banyak pula pekerjaan yang dulu tidak terpikirkan namun sekarang menjadi pekerjaan yang sangat menguntungkan.

Revolusi Industri 4.0 telah banyak membawa perubahan dengan segala konsekuensinya, berjuta peluang terbuka namun secara bersamaan berjuta tantangan juga mengikutinya. Salah satu karakteristik dari revolusi industri 4.0 menerapkan pengaplikasikan kecerdasan buatan atau artificiall intellegent (Tjandarawinata : 2016) Revolusi industri 4.0 merupakan suatu pengaplikasian kecerdasan buatan atau artificial intelligence yang berpotensi untuk meningkatkan pendapatan global dan kualitas hidup bagi masyarakat dunia. Selain itu, artificial intelligence juga akan menghasilkan harga yang murah dan kompetitif, meningkatkan efisiensi dan produktivitas, menurunkan biaya transportasi dan komunikasi, meningkatkan efektivitas logistik dan rantai pasokan global, biaya perdagangan akan berkurang, membuka pasar baru, serta mendorong pertumbuhan ekonomi.

Sumber daya manusia semakin terpinggirkan karena skill mereka tergantikan oleh mesin sebagai dampak dari artificial intelligence. Untuk bisa beradaptasi dengan perubahan yang dibawa oleh revolusi industri 4.0, sumber daya manusia harus memiliki kemampuan yang tidak dapat dilakukan oleh mesin. Agar dapat menghadapi perubahan di masa mendatang, dibutuhkan Sumber daya manusia yang memiliki soft skill seperti kemampuan pemecahan masalah yang kompleks, pikiran yang kritis, kreativitas, manajemen, berkoordinasi dengan orang lain, kecerdasan emosional, penilaian dan pengambilan keputusan, berorientasi servis, negosiasi, dan fleksibilitas kognitif. Soft skill menjadi salah satu faktor yang paling penting untuk dimiliki oleh sumber daya manusia di masa depan. Soft skill merupakan kemampuan di luar kemampuan teknis dan akademis yang lebih mengutamakan kemampuan intrapersonal dan interpersonal. Secara garis besar soft skills merupakan gabungan kemampuan intrapersonal dan kemampuan interpersonal (Purnami : 2013: 99).

"Memiliki Softskills sangat penting dalam dunia kerja karena harus dapat menumbuhkan sikap-sikap yang merujuk pada sekumpulan karakteristik kepribadian. Seperti memiliki sifat tanggung jawab yaitu; disiplin atau selalu datang tepat waktu dalam setiap pertemuan, bekerja 
sampai detik terakhir untuk menyelesaikan tugas, berhati-hati dalam melakukan pekerjaan, dan dapat menepati janji”. (Munandar, 2011).

Sifat soft skills itu invisible tidak bisa segera dilihat langsung oleh orang lain Soft skills apa yang kita miliki. Seperti dapat beradaptasi dengan cepat atau kecakapan memimpin. skills dapat pula dikatagorikan sebagai ketrampilan interpersonal seperti kemampuan berkomunikasi dan bekerja sama dalam sebuah kelompok. Sementara hardskill teknis sifatnya dan umumnya tertulis dalam biodata atau Curiculum Vitae seseorang yang meliputi pendidikan, pengalaman, dan tingkat keahlian (teknis).

Selain soft skill lulusan perguruan tinggi juga harus mempunyai keyakinan bahwa hanya diri merekalah yang dapat menentukan masa depan mereka, sukses atau tidak (locus of control internal). Lulusan yang memiliki locus of control internal mempunyai keyakinan bahwa mereka akan mencapai keberhasilan apabila berusaha keras dengan segala kemampuannya (Fauzan : 2019). Artinya dengan locus of control internal seseorang akan selalu optimis dan percaya diri dalam menghadapi masa depan, termasuk bagi yang baru menyelesaikan pendidikan di perguruan tinggi atau sering disebut dengan fresh graduate.

Robbins dan Judge (2007) mendefinisikan "locus of control internal sebagai tingkat dimana individu yakin bahwa mereka adalah penentu nasib mereka sendiri. Internal adalah individu yang yakin bahwa mereka merupakan pemegang kendali atas apa pun yang terjadi pada diri mereka, sedangkan ekternal adalah individu yang yakin bahwa apapun yang terjadi pada diri mereka dikendalikan oleh kekuatan luar seperti kesempatan dan keberuntungan ataupun bantuan pihak lain".

Berdasarkan pengamatan awal peneliti terhadap alumni yang baru menyelesaikan pendidikan pada program sarjana prodi Manajemen Unihaz Bengkulu, ada semacam kekhawatiran atau sindrom "apa langkah selanjutnya". Kekhawatiran tersebut sepertinya wajar, mengingat mereka baru memulai tahapan berikutnya yaitu untuk mendapatkan pekerjaan. Banyak isu dan informasi yang mereka dengar tentang sumber daya manusia yang kehilangan pekerjaan sebagai dampak dari artificial intelligence di era industri 4.0 sehingga tidak sedikit dari mereka bertanyatanya apa yang dapat saya kerjakan.

\section{Tujuan dan Manfaat Penelitian}

Tujuan penelitian ini secara umum untuk mendukung program pemerintah dalam mengatasi pengangguran di Indonesia. Secara spesifik penelitian ini bertujuan untuk (1) Menanamkan rasa percaya diri bagi fresh graduate dalam era industri 4.0 (2) Tantangan bagi fresh graduate dalam memanfaatkan dampak positif era industri 4.0 (3) Memotivasi bagi fresh graduate untuk memiliki soft skill dan locus of control internal. (4) Merubah paradigma mahasiswa belajar di perguruan tinggi tidak semata-mata untuk mendapatkan hard skill.

Manfaat dari penelitian ini diharapkan (1) Akan menumbuhkan optimisme bagi lulusan prodi manajemen yang baru (2) Pengembangan soft skill dan locus of control internal bagi mahasiswa. 


\section{Tinjauan Pustaka}

Softskills dalam wikipedia merupakan "istilah sosiologis yang merujuk pada sekumpulan karakteristik kepribadian, daya tarik sosial, kemampuan berbahasa, kebiasaan pribadi, kepekaan/kepedulian, serta optimisme". Softskills ini melengkapi hard skills yang bisa dikatakan juga sebagai persyaratan teknis dari suatu pekerjaan. Softskills tersebut meliputi (a) kualitas pribadi misalnya tanggung jawab, kepercayaan diri, kejujuran, berlaku adil, kemampuan bekerja sama, kemampuan berkomunikasi, kemampuan bersosialisasi, manajemen (pengendalian) diri, dan integritas atau kejujuran; dan (b) ketrampilan interpersonal yaitu keterampilan seseorang dalam berinteraksi dengan orang lain yang mampu mengembangkan untuk kerja secara maksimal, misalnya berpartisipasi sebagai anggota kelompok, mengajar (berbagi pengetahuan) ke orang lain, melayani pelanggan, kepemimpinan, kemampuan negosiasi, dan bisa bekerja dalam keragaman.

Soft skills adalah keterampilan seseorang dalam berhubungan dengan orang lain (interpersonal skills) dan keterampilan dalam mengatur dirinya sendiri (intrapersonal skills) untuk kerja secara maksimal. Berthal mengemukakan (Muqowim : 2012 : 5) "Soft skills diartikan sebagai perilaku personal dan interpersonal yang mengembangkan dan memaksimalkan kinerja manusia". Sedangkan menurut Putra dan Pratiwi (2005) "soft skills adalah kemampuankemampuan tak terlihat yang diperlukan untuk sukses, misalnya kemampuan berkomunikasi, kejujuran/integritas dan lain-lain".

Menurut Sailah (2008 : 11) soft skills didefinisikan sebagai "Personal and interpersonal behaviour that develop and maximize human performance (e.g. coaching, team building, initiative, decision making, etc.). Soft skills does not include technical skill such as financial computing and assembly skills. Definisi tersebut dapat dimaknai bahwa perilaku hubungan antar pribadi dan dengan pribadinya sendiri dikembangkan dan kinerja manusianya dioptimalkan (misalnya, forum pelatihan, bekerjasama dalam tim, inisiatif, pengambilan keputusan komunikasi, kemampuan beradaptasi, conflict solution, kepemimpinan, pemecahan masalah, dll.)". Keterampilan teknikal seperti keterampilan perhitungan finansial tidak termasuk dalam Soft skills. Prastiwi memaparkan, "secara umum soft skills diartikan sebagai kemampuan di luar kemampuan teknis dan akademis, yang lebih mengutamakan kemampuan intra dan interpersonal".

Elfindri dkk menjelaskan bahwa "soft skills merupakan sebuah keterampilan dan kecakapan hidup yang harus dimiliki baik untuk sendiri, berkelompok, atau bermasyarakat, serta berhubungan dengan Sang Pencipta. Soft skills sangat diperlukan untuk kecakapan hidup seseorang”. (2011:10).

"Individu dengan internal locus of control yakin bahwa kesuksesan dan kegagalan yang terjadi dalam hidup tergantung pada diri sendiri. Orang yang mempunyai internal locus of control mempunyai keyakinan bahwa apa yang terjadi pada dirinya, kegagalan-kegagalan, keberhasilan-keberhasilannya karena pengaruh dirinya sendiri”. (Sarafino \& Tomothy : 2011). 
Yosefhin Rika Ernima dkk (2016 : 5) "Locus of control atau diartikan sebagai persepsi seseorang tentang penyebab kesuksesan atau kegagalan dalam melaksanakan pekerjaannya. Seseorang memiliki kecenderungan internal locus of control memandang bahw segala sesuatu yang dialaminya, baik yang kurang berbentuk peristiwa, kejadian, nasib atau takdir disebabkan karena kendali dirinya sendiri."

Locus of control terkait dengan tingkat kepercayaan seseorang tentang peristiwa, nasib, keberuntungan dan takdir yang terjadi pada dirinya, apakah karena faktor internal atau faktor eksternal. "Individu yang percaya bahwa peristiwa, kejadian, dan takdir disebabkan karena kendali dirinya sendiri disebut dengan internal locus of control. Sedangkan individu yang percaya bahwa peristiwa, kejadian, dan takdir disebabkan karena kendali dari faktor di luar dirinya disebut dengan eksternal locus of control" (Robbins, 2005).

Kerangka analisa dalam penelitian ini dapat digambarkan dalam skema penelitian sebagai berikut:



Sebagai hipotesa dalam penelitian ini adalah diduga adanya pengaruh soft skill dan locus of control internal terhadap kesiapan fresh graduate prodi manajemen unihaz Bengkulu dalam menyongsong era industri 4.0 baik secara parsial maupun secara simultan.

\section{Metode Penelitian}

Penelitian ini bersifat eksplanatory risearach, yaitu melihat hubungan variabel pengetahuan Soft Skill $\left(\mathrm{X}_{1}\right)$ dan locus of control internal $\left(\mathrm{X}_{2}\right)$ terhadap kesiapan fresh graduate dalam era industri 4.0 (Y) kemudian menguji hipotesa. Dalam penelitian ini data yang digunakan adalah data kuantitatif, dimana data tersebut diperoleh dari hasil penyebaran kuesioner kepada responden untuk diolah kedalam analisa statistik.

Populasi dalam penelitian ini adalah lulusan prodi manajemen Unihaz Bengkulu yang diyudisium pada tahun akademik 2018-2019 berjumlah 82 orang lulusan. Teknik pengambilan samapel non probability sampling, dengan metode totality sampling, yaitu sampel diambil dari keseluruhan populasi yaitu 87 orang lulusan.

Alat analisa yang digunakan dalam penelitian ini adalah (1) Analisa regresi linear berganda, yang digunakan untuk mengetahui seberapa besar pengaruh antara variabel soft skill $\left(\mathrm{X}_{1}\right)$ dan locus of control internal $\left(\mathrm{X}_{2}\right)$ dengan variabel kesiapan fresh graduade dalam era industri 4.0 (Y). Menurut Sugiyono (2013:269) "persamaan regresi linear berganda dengan dua variabel 
independen adalah sebagai berikut :

$\mathrm{Y}=\mathrm{b}_{0}+\mathrm{b}_{1} \mathrm{X}_{1}+$

$\mathrm{b}_{2} \mathrm{X}_{2}+\mathrm{e}$ (2) "korelasi berganda untuk melihat tingkat keeratan atara variabel-varibel independen dengan variabel dependent. (3) koefisein determinasi akan memberikan informasi seberapa besar persentase variasi variabel bebas yang digunakan dalam model mampu menjelaskan variasi variabel terikat". (Prayitno : 2013 : 143). (4) "Pengujian hipotesis yang digunakan dalam penelitian ini ialah uji signifikansi simultan atau uji statistik F dan uji signifikansi parameter individual atau uji statistik t. Uji F untuk menunjukkan apakah semua variabel independen secara simultan berpengaruh pada variabel dependen" (Utama, 2009:69). Uji t dipakai untuk mengetahui seberapa besar pengaruh dari variabel independen secara parsial terhadap variabel dependen (Utama, 2009:68).

\section{Analisa dan Pembahasan}

Berdasarkan hasil analisis data diperoleh nilai

\section{Coefficientsa}

\begin{tabular}{|c|c|c|c|c|c|c|c|c|}
\hline & \multirow{2}{*}{ Model } & \multicolumn{2}{|c|}{$\begin{array}{l}\text { Unstandardized } \\
\text { Coefficients }\end{array}$} & \multirow{2}{*}{\begin{tabular}{|c|}
$\begin{array}{c}\text { Standardized } \\
\text { Coefficients }\end{array}$ \\
Beta
\end{tabular}} & \multirow{2}{*}{$t$} & \multirow{2}{*}{ Sig. } & \multicolumn{2}{|c|}{$\begin{array}{l}\text { Collinearity } \\
\text { Statistics }\end{array}$} \\
\hline & & B & $\begin{array}{l}\text { Std. } \\
\text { Error }\end{array}$ & & & & Tolerance & VIF \\
\hline & (Constant) & 15.143 & 1.431 & & 10.579 & .000 & & \\
\hline & Soft Skill & .183 & .069 & .283 & 2.641 & .010 & .893 & 1.120 \\
\hline & $\begin{array}{l}\text { Locus Of } \\
\text { Control }\end{array}$ & .137 & .057 & .255 & 2.388 & .019 & .893 & 1.12 \\
\hline
\end{tabular}

a. Dependent Variable: Kesiapan Fresh Graduade

Model Summary

\begin{tabular}{|c|c|c|c|c|}
\hline Model & $\mathrm{R}$ & $\mathrm{R}$ Square & $\begin{array}{c}\text { Adjusted R } \\
\text { Square }\end{array}$ & $\begin{array}{c}\text { Std. Error of } \\
\text { the Estimate }\end{array}$ \\
\hline 1 & $.439^{\mathrm{a}}$ & .192 & .172 & 1.01799 \\
\hline
\end{tabular}

a. Predictors: (Constant), Locus Of Control, Soft Skill

\begin{tabular}{|c|c|c|c|c|c|}
\hline \multicolumn{1}{|c|}{ ANOVA $^{\mathrm{b}}$} \\
\hline \multirow{2}{*}{ Model } & $\begin{array}{c}\text { Sum of } \\
\text { Squares }\end{array}$ & $\mathrm{df}$ & Mean Square & $\mathrm{F}$ & Sig. \\
\hline Regression & 19.510 & 2 & 9.755 & 9.413 & $.000^{\mathrm{a}}$ \\
Residual & 81.868 & 79 & 1.036 & & \\
Total & 101.378 & 81 & & & \\
\hline
\end{tabular}

a. Predictors: (Constant), Locus Of Control, Soft Skill

b. Dependent Variable: Kesiapan Fresh Graduade 
Persamaan regresi $\mathrm{Y}=15,143+0,183 \mathrm{X}_{1}+0,137 \mathrm{X}_{2}$ persamaan tersebut menunjukkan bahwa apabila soft skill ditingkatkan satu satuan akan menaikan kesiapan fresh graduate dalam era industri 4.0 sebesar 0,183 satuan, asumsinya locus of control internal tidak mengalami perubahan (konstan). Apa bila locus of control internal ditingkatkan sebesar satu satuan maka kesiapan fresh graduade akan dapat meningkatkan sebesar 0,137 satuan, dengan asumsi soft skill konstan.

Persamaan regresi di atas menunjukkan bahwa kontribusi variabel soft skill terhadap terhadap kesiapan fresh graduate dalam menghadapi era industri 4.0 lebih dominan yaitu sebesar 0,183 . Kondisi ini sejalan dengan penelitian Dini Tiara Tajriani (2019). Adanya kontribusi soft skills terhadap kinerja dapat terjadi apabila karyawan menguasai soft skills yang beraneka ragam sehingga dapat diterapkan sesuai dengan keperluan pekerjaannya.

Demikian pula sebelumnya pada tahun 2002 National Assocition of Colleges (NACE) telah mengadakan survei terhadap 457 orang pengusaha di Amerika Serikat, dari hasil survei tersebut dapat disimpulan bahwa Indeks Prestasi (IP) hanya no 17 dari 20 kualitas penting dari lulusan universitas, sedangkan kualitas yang bersifat tidak terlihat wujudnya (intangible) atau disebut juga dengan soft skill justru yang cenderung dianggap lebih penting. Kualitas lulusan Perguruan Tinggi Yang Diharapkan Dunia Kerja adalah:

\begin{tabular}{llr} 
No & \multicolumn{1}{c}{ Kualitas } & Skor \\
1. & Kemampuan berkomunikasi & 4,69 \\
2. & Kejujuran/Integritas & 4.59 \\
3. & Kemampuan bekerja sama & 4.54 \\
4. & Kemampuan interpersonal & 4,50 \\
5. & Etos kerja yang baik & 4,46 \\
6. & Memiliki motivasi/berinisiatif & 4,42 \\
7. & Mampu beradaptasi & 4,41 \\
8. & Kemampuan analitikal & 4,36 \\
9. & Kemampuan computer & 4,21 \\
10. & Kemampuan berorganisasi & 4,05 \\
11. & Berorientasi pada detail & 4,00 \\
12. & Kemampuan memimpin & 3,97 \\
13. & Percaya diri & 3,95 \\
14. & Berkepribadian ramah & 3,85 \\
15. & Sopan/beretika & 3,82 \\
16. & Bijaksana & 3,75 \\
17. & IP $\geq 3,0$ & 3,68 \\
18. & Kreatif & 3,59 \\
19. & Humoris & 3,25 \\
20. & Kemampuan entrepreneuship & 3,23
\end{tabular}

Sumber: Hasil Survei NACE USA (Putra dan Pratiwi; 2005) 
Kalau kita cermati hasil survei NACE USA tersebut dari 20 kualitas lulusan yang diharapkan dunia kerja sebanyak 19 item berupa soft skill, dan hanya satu yaitu no. 17 (IP $\geq 3,0$ ) yang dikatagorikan hard skill. Artinya soft skill sangat berpengaruh terhadap masa depan lulusan perguruan tinggi. Demikian pula halnya dengan lulusan yang baru menyelesaikan pendidikan (fresh graduate) pada prodi manajeman harus memiliki soft skill yang mumpuni. Terlebih lagi dalam era industri 4.0 dimana artificial intelligence telah mengambil alih sebahagian besar pekerjaan manusia. Artinya sumber daya manusia harus memiliki keterampilan yang tidak dimiliki oleh artificial intelligence yang akan tetap dipertahankan oleh semua bidang usaha, keterampilan tersebut adalah soft skill.

Koefisien locus of control internal sebesar 0,137 artinya bila locus of control internal ditingkatkan satu satuan maka akan menaikan kesiapan fresh graduate dalam era industri 4.0 sebesar 0,137 satuan. Hal ini sejalan dengan beberapa penelitian sebelumnya . Menurut Crider (dalam Ghufron \& Risnawati, 2014) "individu yang memiliki internal locus of control mempunyai ciri-ciri sebagai berikut : (1) Suka bekerja keras (2) Memiliki inisiatif tinggi (3) Selalu berusaha menemukan pemecahan masalah (4) Selalu mencoba berpikir seefektif mungkin (5) Selalu mempunyai persepsi bahwa usaha harus dilakukan jika ingin berhasil".

seseorang yang memiliki locus of control internal, bila mengalami kagagalan, maka dirinya sendirilah yang akan dia salahkan karena usaha yang dia lakukan kurang maksimal. Demikian pula sebaliknya, mereka akan merasa bangga atas hasil usahanya bila mendapatkan kesuksesan atau keberhasilan. Kondisi demikian itu akan berpengaruh positif terhadap aktipitas selanjutnya pada masa yang akan datang, yaitu mereka memiliki kepercayaan akan mencapai kesuksesan apabila berusaha semaksimal mungkin sesuai dengan potensi yang ia miliki. Locus of control internal mengacu pada sudut pandang seseorang mengenai kesuksesan dan kegagalan. Bila seseorang memiliki pengendalian diri yang tinggi, maka ia akan memiliki visi yang jelas dan rencana jangka panjang yang jelas pula. Jika locus of control internal semakin tinggi maka optimismenya dalam era industri 4.0 semakin tinggi pula sekalipun mereka masih digolongkan dalam kelompok fresh graduate.

Uji statistik $t$-test (uji parsial) diketahui nilai t-hitung sebesar 2.641 dengan tingkat significant 0,010 lebih kecil dari level of significant 0,05. Ini artinya soft skill berpengaruh positif terhadap kesiapan fresh graduate dalam era industri 4.0 nilai t-test ini semakin menekankan pentingnya soft skill bagi fresh graduate.

Nilai t-hitung locus of control internal 2,388 dengan tingkat significant 0,019, ini semakin memperkuat pengaruh locus of control internal terhadap kesiapan fresh graduate dalam era industri 4.0

- Korelasi berganda hasil analisa adalah 0,439 artinya hubungan keeratan antara variabel soft skill dan Locus Of Control Internal terhadap kesiapan fresh graduate dalam era industri 4.0,"cukup kuat karena berada pada angka 0,40 - 0,599" (Sugiyono : 2013). Koefisien diterminasi ( $R$ - 
Square) adalah 0,192 artinya 19,20\% soft skill dan Locus Of Control Internal dapat mempengaruhi kesiapan fresh graduate dalam era industri 4.0, sedangkan $80,80 \%$ dipengaruhi oleh variabel yang lain diluar variabel soft skill dan locus of control. Sehingga penelitian yang berkaitan dengan kesiapan menghadapi era industri 4.0 ini masih memerlukan penelitian berkelanjutan dengan variabel-variabel independen yang lain.

Hasil f-test (uji simultan) diperoleh nilai 9,413 dengan tingkat significant 0,000 lebih kecil dari 0,05. Artinya secara serentak (simultan) soft skill dan Locus of Control Internal dapat mempengaruhi kesiapan fresh graduate pada prodi manajemen UNIHAZ Bengkulu dalam era industri 4.0.

\section{Simpulan dan Saran}

Merujuk pada hasil analisa data dan pembahasan didapat simpulan bahwa (1) variabel soft skill $\left(\mathrm{X}_{1}\right)$ dan Locus Of Control Internal $\left(\mathrm{X}_{2}\right)$ berpengaruh positif terhadap kesiapan fresh graduate prodi manajemen dalam era industri 4.0 (Y) hal tersebut dapat dilihat dari koefisien regresi, korelasi berganda, determinasi, uji-t dan uji-f. (2) Variabel soft skill memberikan kontribusi yang lebih besar dibandingkan dengan Locus Of Control Internal dalam menumbuhkan kesiapan fresh graduate dalam era industri 4.0 bagi lulusan prodi manajemen Unihaz Bengkulu.

Sebagai saran karena soft skill dapat menumbuhkan kesiapan dalam era industri 4.0 bagi lulusan yang baru tamat. Maka mahasiswa diberikan pasilitas dan kesempatan untuk mengembangkan soft skill seperti mengikuti organisasi kemahasiswaan, organisasi kerohanian dan mengikuti lombalomba untuk pengembangan diri.

Locus Of Control Internal dapat berpengaruh significant terhadap kesiapan fresh graduate dalam era industri 4.0, maka perlu dibentuk dan dikembangkan rasa percaya diri agar lulusan yang baru menyelesaikan studi tetap optimis dalam menatap masa depan dalam era industri 4.0

\section{REFERENSI}

Dini Tiara Tajriani, 2019. Pengaruh Soft Skill dan Dukungan Sosial Teman Kerja Terhadap Kinerja Pemasaran BMT di Yogyakarta. Indonesian Interdisciplinary Journal of Sharia Economics (IIJSE) Vol. 1. No. 2. Januari 2019 e-ISSN: 2621-606X

Elfindri dkk. 2010. Soft Skill Untuk Tenaga Pendidik. Jakarta: Baduose Media.

Fauzan. 2019. Pengaruh Mata Kuliah Kewirausahaan dan Locus of Control Internal Terhadap Motivasi Berwirausaha Bagi Lulusan Prodi Manajemen Unihaz Bengkulu. Jurnal CRMJ ISSN 2621-1092. Fakultas Ekonomi Prodi Manajemen UNIHAZ Bengkulu

Ghufron, M. \& Rini Risnawati, 2014. Teori-teori psikologi. Yogyakarta: ArRuzz Media Group.

Illah Sailah. 2008. Pengembangan Soft skills Di Perguruan Tinggi. Jakarta:

Direktorat Jenderal Pendidikan Tinggi. 
Priyatno. 2013. Mandiri Belajar Analisis Data Dengan SPSS. Jakarta, Mediakom.

Purnami. 2013"Implementasi Metode Experiental Learning Dalam Pengembangan Softskill Mahasiswa Yang Menunjang Integrasi Teknologi, Manajemen dan Bisnis”. Jurnal Penelitian Pendidikan , Magister Manajemen Bisnis, Sekolah Pascasarjana, Universitas Pendidikan Indonesia. ISSN 1412-565 X Vol. 14

Putra, S. I. \& Pratiwi, A. 2005. Sukses dengan Soft Skill. Bandung: Direktorat Pendidikan Institut Teknologi Bandung.

Tjandrawina, R.R. 2016. Industri 4.0: Revolusi industri abad ini dan pengaruhnya pada bidang kesehatan dan bioteknologi. Jurnal Medicinus, Vol 29.

Yosefhin Rika Ernima dkk. 2016. Jurnal Pendidikan Ekonomi dan Bisnis Vol. 4 